\title{
Some fixed point theorems concerning $F$-contraction in complete metric spaces
}

Hossein Piri ${ }^{1}$ and Poom Kumam² ${ }^{*}$

${ }^{\text {"Correspondence: }}$ poom.kum@kmutt.ac.th;

poom.kumam@mail.kmutt.ac.th ${ }^{2}$ Department of Mathematics, Faculty of Science, King Mongkutís University of Technology Thonburi (KMUTT), 126 Bangmod, Thrung Khru, Bangkok, 10140, Thailand Full list of author information is available at the end of the article

\begin{abstract}
In this paper, we extend the result of Wardowski (Fixed Point Theory Appl. 2012:94, 2012) by applying some weaker conditions on the self map of a complete metric space and on the mapping $F$, concerning the contractions defined by Wardowski. With these weaker conditions, we prove a fixed point result for F-Suzuki contractions which generalizes the result of Wardowski.
\end{abstract}

MSC: $74 \mathrm{H} 10 ; 54 \mathrm{H} 25$

Keywords: fixed point; metric space; F-contraction

\section{Introduction and preliminaries}

Throughout this article, we denote by $\mathbb{R}$ the set of all real numbers, by $\mathbb{R}_{+}$the set of all positive real numbers, and by $\mathbb{N}$ the set of all natural numbers.

In 1922, Polish mathematician Banach [1] proved a very important result regarding a contraction mapping, known as the Banach contraction principle. It is one of the fundamental results in fixed point theory. Due to its importance and simplicity, several authors have obtained many interesting extensions and generalizations of the Banach contraction principle (see [2-9] and references therein). Subsequently, in 1962, M Edelstein proved the following version of the Banach contraction principle.

Theorem 1.1 [10] Let $(X, d)$ be a compact metric space and let $T: X \rightarrow X$ be a selfmapping. Assume that $d(T x, T y)<d(x, y)$ holds for all $x, y \in X$ with $x \neq y$. Then $T$ has a unique fixed point in $X$.

In 2008, Suzuki [2] proved generalized versions of Edelstein's results in compact metric space as follows.

Theorem 1.2 [2] Let $(X, d)$ be a compact metric space and let $T: X \rightarrow X$ be a self-mapping. Assume that for all $x, y \in X$ with $x \neq y$,

$$
\frac{1}{2} d(x, T x)<d(x, y) \quad \Rightarrow \quad d(T x, T y)<d(x, y) .
$$

Then $T$ has a unique fixed point in $X$.

In 2012, Wardowski [11] introduce a new type of contractions called $F$-contraction and prove a new fixed point theorem concerning $F$-contractions. In this way, Wardowski [11]

\section{Springer}

(02014 Piri and Kumam; licensee Springer. This is an Open Access article distributed under the terms of the Creative Commons Attribution License (http://creativecommons.org/licenses/by/2.0), which permits unrestricted use, distribution, and reproduction in any medium, provided the original work is properly cited. 
generalized the Banach contraction principle in a different manner from the well-known results from the literature. Wardowski defined the $F$-contraction as follows.

Definition 1.3 Let $(X, d)$ be a metric space. A mapping $T: X \rightarrow X$ is said to be an $F$ contraction if there exists $\tau>0$ such that

$$
\forall x, y \in X, \quad[d(T x, T y)>0 \Rightarrow \tau+F(d(T x, T y)) \leq F(d(x, y))]
$$

where $F: \mathbb{R}_{+} \rightarrow \mathbb{R}$ is a mapping satisfying the following conditions:

(F1) $F$ is strictly increasing, i.e. for all $x, y \in \mathbb{R}_{+}$such that $x<y, F(x)<F(y)$;

(F2) For each sequence $\left\{\alpha_{n}\right\}_{n=1}^{\infty}$ of positive numbers, $\lim _{n \rightarrow \infty} \alpha_{n}=0$ if and only if $\lim _{n \rightarrow \infty} F\left(\alpha_{n}\right)=-\infty ;$

(F3) There exists $k \in(0,1)$ such that $\lim _{\alpha \rightarrow 0^{+}} \alpha^{k} F(\alpha)=0$.

We denote by $\mathcal{F}$, the set of all functions satisfying the conditions (F1)-(F3). For examples of the function $F$ the reader is referred to [12] and [11].

Remark 1.4 From (F1) and (1) it is easy to conclude that every $F$-contraction is necessarily continuous.

Wardowski [11] stated a modified version of the Banach contraction principle as follows.

Theorem 1.5 [11] Let $(X, d)$ be a complete metric space and let $T: X \rightarrow X$ be an Fcontraction. Then $T$ has a unique fixed point $x^{*} \in X$ and for every $x \in X$ the sequence $\left\{T^{n} x\right\}_{n \in \mathbb{N}}$ converges to $x^{*}$.

Very recently, Secelean [12] proved the following lemma.

Lemma 1.6 [12] Let $F: \mathbb{R}_{+} \rightarrow \mathbb{R}$ be an increasing mapping and $\left\{\alpha_{n}\right\}_{n=1}^{\infty}$ be a sequence of positive real numbers. Then the following assertions hold:

(a) if $\lim _{n \rightarrow \infty} F\left(\alpha_{n}\right)=-\infty$, then $\lim _{n \rightarrow \infty} \alpha_{n}=0$;

(b) if inf $F=-\infty$, and $\lim _{n \rightarrow \infty} \alpha_{n}=0$, then $\lim _{n \rightarrow \infty} F\left(\alpha_{n}\right)=-\infty$.

By proving Lemma 1.6, Secelean showed that the condition (F2) in Definition 1.3 can be replaced by an equivalent but a more simple condition,

$\left(\mathrm{F}^{\prime}\right) \inf F=-\infty$

or, also, by

$\left(\mathrm{F} 2^{\prime \prime}\right)$ there exists a sequence $\left\{\alpha_{n}\right\}_{n=1}^{\infty}$ of positive real numbers such that $\lim _{n \rightarrow \infty} F\left(\alpha_{n}\right)=$ $-\infty$.

Remark 1.7 Define $F_{B}: \mathbb{R}_{+} \rightarrow \mathbb{R}$ by $F_{B}(\alpha)=\ln \alpha$, then $F_{B} \in \mathcal{F}$. Note that with $F=F_{B}$ the $F$-contraction reduces to a Banach contraction. Therefore, the Banach contractions are a particular case of $F$-contractions. Meanwhile there exist $F$-contractions which are not Banach contractions (see $[11,12])$.

In this paper, we use the following condition instead of the condition (F3) in Definition 1.3: 
$($ F3') $F$ is continuous on $(0, \infty)$.

We denote by $\mathfrak{F}$ the set of all functions satisfying the conditions (F1), (F2'), and (F3').

Example 1.8 Let $F_{1}(\alpha)=\frac{-1}{\alpha}, F_{2}(\alpha)=\frac{-1}{\alpha}+\alpha, F_{3}(\alpha)=\frac{1}{1-e^{\alpha}}, F_{4}(\alpha)=\frac{1}{e^{\alpha}-e^{-\alpha}}$. Then $F_{1}, F_{2}, F_{3}$, $F_{4} \in \mathfrak{F}$.

Remark 1.9 Note that the conditions (F3) and (F3') are independent of each other. Indeed, for $p \geq 1, F(\alpha)=\frac{-1}{\alpha^{p}}$ satisfies the conditions (F1) and (F2) but it does not satisfy (F3), while it satisfies the condition $\left(\mathrm{F}^{\prime}\right)$. Therefore, $\mathfrak{F} \not \mathcal{F}$. Again, for $a>1, t \in(0,1 / a), F(\alpha)=\frac{-1}{(\alpha+[\alpha])^{t}}$, where $[\alpha]$ denotes the integral part of $\alpha$, satisfies the conditions (F1) and (F2) but it does not satisfy (F3'), while it satisfies the condition (F3) for any $k \in(1 / a, 1)$. Therefore, $\mathcal{F} \nsubseteq \mathfrak{F}$. Also, if we take $F(\alpha)=\ln \alpha$, then $F \in \mathcal{F}$ and $F \in \mathfrak{F}$. Therefore, $\mathcal{F} \cap \mathfrak{F} \neq \emptyset$.

In view of Remark 1.9, it is meaningful to consider the result of Wardowski [11] with the mappings $F \in \mathfrak{F}$ instead $F \in \mathcal{F}$. Also, we define the $F$-Suzuki contraction as follows and we give a new version of Theorem 1.5.

Definition 1.10 Let $(X, d)$ be a metric space. A mapping $T: X \rightarrow X$ is said to be an $F$ Suzuki contraction if there exists $\tau>0$ such that for all $x, y \in X$ with $T x \neq T y$

$$
\frac{1}{2} d(x, T x)<d(x, y) \quad \Rightarrow \quad \tau+F(d(T x, T y)) \leq F(d(x, y)),
$$

where $F \in \mathfrak{F}$.

\section{Main results}

Theorem 2.1 Let $T$ be a self-mapping of a complete metric space $X$ into itself. Suppose $F \in \mathfrak{F}$ and there exists $\tau>0$ such that

$$
\forall x, y \in X, \quad[d(T x, T y)>0 \Rightarrow \tau+F(d(T x, T y)) \leq F(d(x, y))]
$$

Then $T$ has a unique fixed point $x^{*} \in X$ and for every $x_{0} \in X$ the sequence $\left\{T^{n} x_{0}\right\}_{n=1}^{\infty}$ converges to $x^{*}$.

Proof Choose $x_{0} \in X$ and define a sequence $\left\{x_{n}\right\}_{n=1}^{\infty}$ by

$$
x_{1}=T x_{0}, \quad x_{2}=T x_{1}=T^{2} x_{0}, \quad \ldots, \quad x_{n+1}=T x_{n}=T^{n+1} x_{0}, \quad \forall n \in \mathbb{N} .
$$

If there exists $n \in \mathbb{N}$ such that $d\left(x_{n}, T x_{n}\right)=0$, the proof is complete. So, we assume that

$$
0<d\left(x_{n}, T x_{n}\right)=d\left(T x_{n-1}, T x_{n}\right), \quad \forall n \in \mathbb{N} .
$$

For any $n \in \mathbb{N}$ we have

$$
\tau+F\left(d\left(T x_{n-1}, T x_{n}\right)\right) \leq F\left(d\left(x_{n-1}, x_{n}\right)\right),
$$

i.e.,

$$
F\left(d\left(T x_{n-1}, T x_{n}\right)\right) \leq F\left(d\left(x_{n-1}, x_{n}\right)\right)-\tau \text {. }
$$


Repeating this process, we get

$$
\begin{aligned}
F\left(d\left(T x_{n-1}, T x_{n}\right)\right) & \leq F\left(d\left(x_{n-1}, x_{n}\right)\right)-\tau \\
& =F\left(d\left(T x_{n-2}, T x_{n-1}\right)\right)-\tau \\
& \leq F\left(d\left(x_{n-2}, x_{n-1}\right)\right)-2 \tau \\
& =F\left(d\left(T x_{n-3}, T x_{n-2}\right)\right)-2 \tau \\
& \leq F\left(d\left(x_{n-3}, x_{n-2}\right)\right)-3 \tau \\
& \vdots \\
& \leq F\left(d\left(x_{0}, x_{1}\right)\right)-n \tau .
\end{aligned}
$$

From (4), we obtain $\lim _{n \rightarrow \infty} F\left(d\left(T x_{n-1}, T x_{n}\right)\right)=-\infty$, which together with $\left(\mathrm{F} 2^{\prime}\right)$ and Lemma 1.6 gives $\lim _{n \rightarrow \infty} d\left(T x_{n-1}, T x_{n}\right)=0$, i.e.,

$$
\lim _{n \rightarrow \infty} d\left(x_{n}, T x_{n}\right)=0
$$

Now, we claim that $\left\{x_{n}\right\}_{n=1}^{\infty}$ is a Cauchy sequence. Arguing by contradiction, we assume that there exist $\epsilon>0$ and sequences $\{p(n)\}_{n=1}^{\infty}$ and $\{q(n)\}_{n=1}^{\infty}$ of natural numbers such that

$$
p(n)>q(n)>n, \quad d\left(x_{p(n)}, x_{q(n)}\right) \geq \epsilon, \quad d\left(x_{p(n)-1}, x_{q(n)}\right)<\epsilon, \quad \forall n \in \mathbb{N} .
$$

So, we have

$$
\begin{aligned}
\epsilon & \leq d\left(x_{p(n)}, x_{q(n)}\right) \leq d\left(x_{p(n)}, x_{p(n)-1}\right)+d\left(x_{p(n)-1}, x_{q(n)}\right) \\
& \leq d\left(x_{p(n)}, x_{p(n)-1}\right)+\epsilon \\
& =d\left(x_{p(n)-1}, T x_{p(n)-1}\right)+\epsilon .
\end{aligned}
$$

It follows from (5) and the above inequality that

$$
\lim _{n \rightarrow \infty} d\left(x_{p(n)}, x_{q(n)}\right)=\epsilon
$$

On the other hand, from (5) there exists $N \in \mathbb{N}$, such that

$$
d\left(x_{p(n)}, T x_{p(n)}\right)<\frac{\epsilon}{4} \quad \text { and } \quad d\left(x_{q(n)}, T x_{q(n)}\right)<\frac{\epsilon}{4}, \quad \forall n \geq N
$$

Next, we claim that

$$
d\left(T x_{p(n)}, T x_{q(n)}\right)=d\left(x_{p(n)+1}, x_{q(n)+1}\right)>0, \quad \forall n \geq N .
$$

Arguing by contradiction, there exists $m \geq N$ such that

$$
d\left(x_{p(m)+1}, x_{q(m)+1}\right)=0 .
$$


It follows from (6), (8), and (10) that

$$
\begin{aligned}
\epsilon & \leq d\left(x_{p(m)}, x_{q(m)}\right) \leq d\left(x_{p(m)}, x_{p(m)+1}\right)+d\left(x_{p(m)+1}, x_{q(m)}\right) \\
& \leq d\left(x_{p(m)}, x_{p(m)+1}\right)+d\left(x_{p(m)+1}, x_{q(m)+1}\right)+d\left(x_{q(m)+1}, x_{q(m)}\right) \\
& =d\left(x_{p(m)}, T x_{p(m)}\right)+d\left(x_{p(m)+1}, x_{q(m)+1}\right)+d\left(x_{q(m)}, T x_{q(m)}\right) \\
& <\frac{\epsilon}{4}+0+\frac{\epsilon}{4}=\frac{\epsilon}{2} .
\end{aligned}
$$

This contradiction establishes the relation (9). Therefore, it follows from (9) and the assumption of the theorem that

$$
\tau+F\left(d\left(T x_{p(n)}, T x_{q(n)}\right)\right) \leq F\left(d\left(x_{p(n)}, x_{q(n)}\right)\right), \quad \forall n \geq N
$$

From (F3'), (7), and (11), we get $\tau+F(\epsilon) \leq F(\epsilon)$. This contradiction shows that $\left\{x_{n}\right\}_{n=1}^{\infty}$ is a Cauchy sequence. By completeness of $(X, d),\left\{x_{n}\right\}_{n=1}^{\infty}$ converges to some point $x$ in $X$. Finally, the continuity of $T$ yields

$$
d(T x, x)=\lim _{n \rightarrow \infty} d\left(T x_{n}, x_{n}\right)=\lim _{n \rightarrow \infty} d\left(x_{n+1}, x_{n}\right)=d\left(x^{*}, x^{*}\right)=0 .
$$

Now, let us to show that $T$ has at most one fixed point. Indeed, if $x, y \in X$ be two distinct fixed points of $T$, that is, $T x=x \neq y=T y$. Therefore,

$$
d(T x, T y)=d(x, y)>0,
$$

then we get

$$
F(d(x, y))=F(d(T x, T y))<\tau+F(d(T x, T y)) \leq F(d(x, y))
$$

which is a contradiction. Therefore, the fixed point is unique.

Theorem 2.2 Let $(X, d)$ be a complete metric space and $T: X \rightarrow X$ be an F-Suzuki contraction. Then $T$ has a unique fixed point $x^{*} \in X$ and for every $x_{0} \in X$ the sequence $\left\{T^{n} x_{0}\right\}_{n=1}^{\infty}$ converges to $x^{*}$.

Proof Choose $x_{0} \in X$ and define a sequence $\left\{x_{n}\right\}_{n=1}^{\infty}$ by

$$
x_{1}=T x_{0}, \quad x_{2}=T x_{1}=T^{2} x_{0}, \quad \ldots, \quad x_{n+1}=T x_{n}=T^{n+1} x_{0}, \quad \forall n \in \mathbb{N} .
$$

If there exists $n \in \mathbb{N}$ such that $d\left(x_{n}, T x_{n}\right)=0$, the proof is complete. So, we assume that

$$
0<d\left(x_{n}, T x_{n}\right), \quad \forall n \in \mathbb{N} .
$$

Therefore,

$$
\frac{1}{2} d\left(x_{n}, T x_{n}\right)<d\left(x_{n}, T x_{n}\right), \quad \forall n \in \mathbb{N} .
$$


For any $n \in \mathbb{N}$ we have

$$
\tau+F\left(d\left(T x_{n}, T^{2} x_{n}\right)\right) \leq F\left(d\left(x_{n}, T x_{n}\right)\right)
$$

i.e.,

$$
F\left(d\left(x_{n+1}, T x_{n+1}\right)\right) \leq F\left(d\left(x_{n}, T x_{n}\right)\right)-\tau .
$$

Repeating this process, we get

$$
\begin{aligned}
F\left(d\left(x_{n}, T x_{n}\right)\right) & \leq F\left(d\left(x_{n-1}, T x_{n-1}\right)\right)-\tau \\
& \leq F\left(d\left(x_{n-2}, T x_{n-2}\right)\right)-2 \tau \\
& \leq F\left(d\left(x_{n-3}, T x_{n-3}\right)\right)-3 \tau \\
& \vdots \\
& \leq F\left(d\left(x_{0}, T x_{0}\right)\right)-n \tau .
\end{aligned}
$$

From (14), we obtain $\lim _{m \rightarrow \infty} F\left(d\left(x_{n}, T x_{n}\right)\right)=-\infty$, which together with (F2') and Lemma 1.6 gives

$$
\lim _{m \rightarrow \infty} d\left(x_{n}, T x_{n}\right)=0
$$

Now, we claim that $\left\{x_{n}\right\}_{n=1}^{\infty}$ is a Cauchy sequence. Arguing by contradiction, we assume that there exist $\epsilon>0$ and sequences $\{p(n)\}_{n=1}^{\infty}$ and $\{q(n)\}_{n=1}^{\infty}$ of natural numbers such that

$$
p(n)>q(n)>n, \quad d\left(x_{p(n)}, x_{q(n)}\right) \geq \epsilon, \quad d\left(x_{p(n)-1}, x_{q(n)}\right)<\epsilon, \quad \forall n \in \mathbb{N} .
$$

So, we have

$$
\begin{aligned}
\epsilon & \leq d\left(x_{p(n)}, x_{q(n)}\right) \leq d\left(x_{p(n)}, x_{p(n)-1}\right)+d\left(x_{p(n)-1}, x_{q(n)}\right) \\
& \leq d\left(x_{p(n)}, x_{p(n)-1}\right)+\epsilon \\
& =d\left(x_{p(n)-1}, T x_{p(n)-1}\right)+\epsilon .
\end{aligned}
$$

It follows from (15) and the above inequality that

$$
\lim _{n \rightarrow \infty} d\left(x_{p(n)}, x_{q(n)}\right)=\epsilon
$$

From (15) and (17), we can choose a positive integer $N \in \mathbb{N}$ such that

$$
\frac{1}{2} d\left(x_{p(n)}, T x_{p(n)}\right)<\frac{1}{2} \epsilon<d\left(x_{p(n)}, x_{q(n)}\right), \quad \forall n \geq N
$$

So, from the assumption of the theorem, we get

$$
\tau+F\left(d\left(T x_{p(n)}, T x_{q(n)}\right)\right) \leq F\left(d\left(x_{p(n)}, x_{q(n)}\right)\right), \quad \forall n \geq N
$$


It follows from (12) that

$$
\tau+F\left(d\left(x_{p(n)+1}, T x_{q(n)+1}\right)\right) \leq F\left(d\left(x_{p(n)}, x_{q(n)}\right)\right), \quad \forall n \geq N
$$

From (F3'), (15), and (18), we get $\tau+F(\epsilon) \leq F(\epsilon)$. This contradiction shows that $\left\{x_{n}\right\}_{n=1}^{\infty}$ is a Cauchy sequence. By completeness of $(X, d),\left\{x_{n}\right\}_{n=1}^{\infty}$ converges to some point $x^{*}$ in $X$. Therefore,

$$
\lim _{n \rightarrow \infty} d\left(x_{n}, x^{*}\right)=0
$$

Now, we claim that

$$
\frac{1}{2} d\left(x_{n}, T x_{n}\right)<d\left(x_{n}, x^{*}\right) \quad \text { or } \quad \frac{1}{2} d\left(T x_{n}, T^{2} x_{n}\right)<d\left(T x_{n}, x^{*}\right), \quad \forall n \in \mathbb{N} \text {. }
$$

Again, assume that there exists $m \in \mathbb{N}$ such that

$$
\frac{1}{2} d\left(x_{m}, T x_{m}\right) \geq d\left(x_{m}, x^{*}\right) \text { and } \frac{1}{2} d\left(T x_{m}, T^{2} x_{m}\right) \geq d\left(T x_{m}, x^{*}\right) .
$$

Therefore,

$$
2 d\left(x_{m}, x^{*}\right) \leq d\left(x_{m}, T x_{m}\right) \leq d\left(x_{m}, x^{*}\right)+d\left(x^{*}, T x_{m}\right),
$$

which implies that

$$
d\left(x_{m}, x^{*}\right) \leq d\left(x^{*}, T x_{m}\right) .
$$

It follows from (21) and (22) that

$$
d\left(x_{m}, x^{*}\right) \leq d\left(x^{*}, T x_{m}\right) \leq \frac{1}{2} d\left(T x_{m}, T^{2} x_{m}\right) .
$$

Since $\frac{1}{2} d\left(x_{m}, T x_{m}\right)<d\left(x_{m}, T x_{m}\right)$, by the assumption of the theorem, we get

$$
\tau+F\left(d\left(T x_{m}, T^{2} x_{m}\right)\right) \leq F\left(d\left(x_{m}, T x_{m}\right)\right) .
$$

Since $\tau>0$, this implies that

$$
F\left(d\left(T x_{m}, T^{2} x_{m}\right)\right)<F\left(d\left(x_{m}, T x_{m}\right)\right) .
$$

So, from (F1), we get

$$
d\left(T x_{m}, T^{2} x_{m}\right)<d\left(x_{m}, T x_{m}\right) .
$$

It follows from (21), (23), and (24) that

$$
\begin{aligned}
d\left(T x_{m}, T^{2} x_{m}\right) & <d\left(x_{m}, T x_{m}\right) \\
& \leq d\left(x_{m}, x^{*}\right)+d\left(x^{*}, T x_{m}\right)
\end{aligned}
$$




$$
\begin{aligned}
& \leq \frac{1}{2} d\left(T x_{m}, T^{2} x_{m}\right)+\frac{1}{2} d\left(T x_{m}, T^{2} x_{m}\right) \\
& =d\left(T x_{n}, T^{2} x_{n}\right) .
\end{aligned}
$$

This is a contradiction. Hence, (20) holds. So, from (20), for every $n \in \mathbb{N}$, either

$$
\tau+F\left(d\left(T x_{n}, T x^{*}\right)\right) \leq F\left(d\left(x_{n}, x^{*}\right)\right)
$$

or

$$
\tau+F\left(d\left(T^{2} x_{n}, T x^{*}\right)\right) \leq F\left(d\left(T x_{n}, x^{*}\right)\right)=F\left(d\left(x_{n+1}, x^{*}\right)\right)
$$

holds. In the first case, from (19), (F2'), and Lemma 1.6, we obtain

$$
\lim _{n \rightarrow \infty} F\left(d\left(T x_{n}, T x^{*}\right)\right)=-\infty
$$

It follows from $\left(\mathrm{F} 2^{\prime}\right)$ and Lemma 1.6 that $\lim _{n \rightarrow \infty} d\left(T x_{n}, T x^{*}\right)=0$. Therefore,

$$
d\left(x^{*}, T x^{*}\right)=\lim _{n \rightarrow \infty} d\left(x_{n+1}, T x^{*}\right)=\lim _{n \rightarrow \infty} d\left(T x_{n}, T x^{*}\right)=0 .
$$

Also, in the second case, from (19), (F2'), and Lemma 1.6, we obtain

$$
\lim _{n \rightarrow \infty} F\left(d\left(T^{2} x_{n}, T x^{*}\right)\right)=-\infty
$$

It follows from $\left(\mathrm{F}^{\prime}\right)$ and Lemma 1.6 that $\lim _{n \rightarrow \infty} d\left(T x_{n}, T x^{*}\right)=0$. Therefore,

$$
d\left(x^{*}, T x^{*}\right)=\lim _{n \rightarrow \infty} d\left(x_{n+2}, T x^{*}\right)=\lim _{n \rightarrow \infty} d\left(T^{2} x_{n}, T x^{*}\right)=0 .
$$

Hence, $x^{*}$ is a fixed point of $T$. Now let us show that $T$ has at most one fixed point. Indeed, if $x^{*}, y^{*} \in X$ are two distinct fixed points of $T$, that is, $T x^{*}=x^{*} \neq y^{*}=T y^{*}$, then $d\left(x^{*}, y^{*}\right)>0$. So, we have $0=\frac{1}{2} d\left(x^{*}, T x^{*}\right)<d\left(x^{*}, y^{*}\right)$ and from the assumption of the theorem, we obtain

$$
F\left(d\left(x^{*}, y^{*}\right)\right)=F\left(d\left(T x^{*}, T y^{*}\right)\right)<\tau+F\left(d\left(T x^{*}, T y^{*}\right)\right) \leq F\left(d\left(x^{*}, y^{*}\right)\right)
$$

which is a contradiction. Thus, the fixed point is unique.

Example 2.3 Consider the sequence $\left\{S_{n}\right\}_{n \in \mathbb{N}}$ as follows:

$$
\begin{aligned}
& S_{1}=1 \times 2, \quad S_{2}=1 \times 2+2 \times 3, \quad \ldots, \\
& S_{n}=1 \times 2+2 \times 3+\cdots+n(n+1)=\frac{n(n+1)(n+2)}{3},
\end{aligned}
$$

Let $X=\left\{S_{n}: n \in \mathbb{N}\right\}$ and $d(x, y)=|x-y|$. Then $(X, d)$ is complete metric space. Define the mapping $T: X \rightarrow X$ by $T\left(S_{1}\right)=S_{1}$ and $T\left(S_{n}\right)=S_{n-1}$ for every $n>1$. Since

$$
\lim _{n \rightarrow \infty} \frac{d\left(T\left(S_{n}\right), T\left(S_{1}\right)\right)}{d\left(S_{n}, S_{1}\right)}=\lim _{n \rightarrow \infty} \frac{S_{n-1}-2}{S_{n}-2}=\frac{(n-1) n(n+1)-6}{n(n+1)(n+2)-6}=1,
$$


$T$ is not a Banach contraction and a Suzuki contraction. On the other hand taking $F(\alpha)=$ $\frac{-1}{\alpha}+\alpha \in \mathfrak{F}$, we obtain the result that $T$ is an $F$-contraction with $\tau=6$. To see this, let us consider the following calculation. First observe that

$$
\frac{1}{2} d\left(S_{n}, T S_{n}\right)<d\left(S_{n}, S_{m}\right) \quad \Leftrightarrow \quad[(1=n<m) \vee(1 \leq m<n) \vee(1<n<m)] .
$$

For $1=n<m$, we have

$$
\begin{aligned}
& \left|T\left(S_{m}\right)-T\left(S_{1}\right)\right|=\left|S_{m-1}-S_{1}\right|=2 \times 3+3 \times 4+\cdots+(m-1) m, \\
& \left|S_{m}-S_{1}\right|=2 \times 3+3 \times 4+\cdots+m(m+1) .
\end{aligned}
$$

Since $m>1$ and $\frac{-1}{2 \times 3+3 \times 4+\cdots+(m-1) m}<\frac{-1}{2 \times 3+3 \times 4+\cdots+m(m+1)}$, we have

$$
\begin{aligned}
6 & -\frac{1}{2 \times 3+3 \times 4+\cdots+(m-1) m}+[2 \times 3+3 \times 4+\cdots+(m-1) m] \\
& <6-\frac{1}{2 \times 3+3 \times 4+\cdots+m(m+1)}+[2 \times 3+3 \times 4+\cdots+(m-1) m] \\
& \leq-\frac{1}{2+3+\cdots+m}+[2 \times 3+3 \times 4+\cdots+(m-1) m]+m(m+1) \\
& =-\frac{1}{2+3+\cdots+m}+[2 \times 3+3 \times 4+\cdots+(m-1) m+m(m+1)] .
\end{aligned}
$$

So, from (25), we get

$$
6-\frac{1}{\left|T\left(S_{m}\right)-T\left(S_{1}\right)\right|}+\left|T\left(S_{m}\right)-T\left(S_{1}\right)\right|<-\frac{1}{\left|S_{m}-S_{1}\right|}+\left|S_{m}-S_{1}\right| .
$$

For $1 \leq m<n$, similar to $1=n<m$, we have

$$
6-\frac{1}{\left|T\left(S_{m}\right)-T\left(S_{1}\right)\right|}+\left|T\left(S_{m}\right)-T\left(S_{1}\right)\right|<-\frac{1}{\left|S_{m}-S_{1}\right|}+\left|S_{m}-S_{1}\right| .
$$

For $1<n<m$, we have

$$
\begin{aligned}
& \left|T\left(S_{m}\right)-T\left(S_{n}\right)\right|=n(n+1)+(n+1)(n+2)+\cdots+(m-1) m, \\
& \left|S_{m}-S_{n}\right|=(n+1)(n+2)+(n+2)(n+3)+\cdots+m(m+1) .
\end{aligned}
$$

Since $m>n>1$, we have

$$
(m+1) m \geq(n+2)(n+1)=n(n+1)+2(n+1) \geq n(n+1)+6 .
$$

We know that $\frac{-1}{n(n+1)+(n+1)(n+2)+\cdots+(m-1) m}<\frac{-1}{(n+1)(n+2)+(n+2)(n+3)+\cdots+m(m+1)}$. Therefore

$$
\begin{aligned}
6- & \frac{1}{n(n+1)+(n+1)(n+2)+\cdots+(m-1) m} \\
& +[n(n+1)+(n+1)(n+2)+\cdots+(m-1) m]
\end{aligned}
$$




$$
\begin{aligned}
< & 6-\frac{1}{(n+1)(n+2)+(n+2)(n+3)+\cdots+m(m+1)} \\
& +[n(n+1)+(n+1)(n+2)+\cdots+(m-1) m] \\
= & -\frac{1}{(n+1)(n+2)+(n+2)(n+3) \cdots+m(m+1)} \\
& +6+n(n+1)+[(n+1)(n+2)+\cdots+(m-1) m] \\
\leq & -\frac{1}{(n+1)(n+2)+(n+2)(n+3)+\cdots+m(m+1)} \\
& +m(m+1)+[(n+1)(n+2)+\cdots+(m-1) m] \\
= & -\frac{1}{(n+1)(n+2)+(n+2)(n+3)+\cdots+m(m+1)} \\
& +[(n+1)(n+2)+\cdots+(m-1) m] .
\end{aligned}
$$

So from (26), we get

$$
6-\frac{1}{\left|T\left(S_{m}\right)-T\left(S_{n}\right)\right|}+\left|T\left(S_{m}\right)-T\left(S_{n}\right)\right|<-\frac{1}{\left|S_{m}-S_{n}\right|}+\left|S_{m}-S_{n}\right| .
$$

\begin{tabular}{|c|c|c|c|c|c|}
\hline$n$ & $x_{n}$ & $C_{F_{1}}$ & $C_{F_{2}}$ & $C_{F_{3}}$ & $C_{F_{4}}$ \\
\hline 3 & 7308 & 1.098612 & 13.09861 & 12.111111 & 12.12201 \\
\hline 4 & 6552 & 0.727214 & 20.74721 & 20.02924 & 20.05196 \\
\hline 5 & 5850 & 0.581922 & 30.58192 & 30.01161 & 30.02896 \\
\hline : & : & : & : & : & : \\
\hline 27 & 20 & 0.109231 & 756.1092 & 756.0000 & 756.0005 \\
\hline 28 & 8 & 0.105388 & 812.1054 & 812.0000 & 812.0004 \\
\hline 29 & 2 & 0.101807 & 870.1018 & 870.0000 & 870.0004 \\
\hline 30 & 2 & 0.09846093 & 930.0983 & 930 & 930.0004 \\
\hline 31 & 2 & 0.0923895 & 1056.092 & 1056 & 1056 \\
\hline 32 & 2 & 0.08962648 & 1122.09 & 1122 & 1122 \\
\hline 33 & 2 & 0.08702411 & 1190.087 & 1190 & 1190 \\
\hline : & $:$ & : & $:$ & : & : \\
\hline 314 & 2 & 0.00953902 & 98910.01 & 98910 & 98910 \\
\hline 315 & 2 & 0.00950879 & 99540.01 & 99540 & 99540 \\
\hline 316 & 2 & 0.00947875 & 100172 & 100172 & 100172 \\
\hline 317 & 2 & 0.00944889 & 100806 & 100806 & 100806 \\
\hline 318 & 2 & 0.00941922 & 101442 & 101442 & 101442 \\
\hline : & : & : & : & : & : \\
\hline & $:$ & $:$ & $:$ & $:$ & $:$ \\
\hline $3 \times 10^{3}$ & 2 & 0.00099983 & 9003000 & 9003000 & 9003000 \\
\hline$n \rightarrow \infty$ & $T(2)=2$ & tends to 0 & $\geq \tau=1$ & $\geq \tau=1$ & $\geq \tau=1$ \\
\hline
\end{tabular}

Therefore $\tau+F\left(d\left(T\left(S_{m}\right), T\left(S_{n}\right)\right)\right) \leq d\left(S_{m}, S_{n}\right)$ for all $m, n \in \mathbb{N}$. Hence $T$ is an $F$-contraction and $T\left(S_{1}\right)=S_{1}$.

For $F_{1}(\alpha)=\ln (\alpha), F_{2}(\alpha)=\ln (\alpha)+\alpha, F_{3}(\alpha)=\frac{-1}{\alpha}+\alpha$, and $F_{4}(\alpha)=\frac{-1}{\sqrt{\alpha+[\alpha]}}+\alpha$ in the above example, we compare the rate of convergence of the Banach contraction ( $F_{1}$-contraction) and $F$-contractions for $F_{2} \in \mathcal{F} \cap \mathfrak{F}, F_{3} \in(\mathfrak{F}-\mathcal{F})$, and $F_{4} \in(\mathcal{F}-\mathfrak{F})$ in Table 1 .

Table 1 The generated iterations start from a point $x_{0}=S_{30} . C_{F}$ denotes $F\left(d\left(S_{1}, S_{n}\right)\right)-F\left(d\left(T\left(S_{1}\right), T\left(S_{n}\right)\right)\right)$ 


\section{Competing interests}

The authors declare that they have no competing interests.

\section{Authors' contributions}

All authors contributed equally and significantly in writing this paper. All authors read and approved the final manuscript.

\section{Author details}

${ }^{1}$ Department of Mathematics, University of Bonab, Bonab, 5551761167, Iran. ${ }^{2}$ Department of Mathematics, Faculty of

Science, King Mongkutís University of Technology Thonburi (KMUTT), 126 Bangmod, Thrung Khru, Bangkok, 10140,

Thailand.

\section{Acknowledgements}

The second author was supported by the Higher Education Research Promotion and National Research University Project of Thailand, Office of the Higher Education Commission (Under NUR Project 'Theoretical and Computational fixed points for Optimization problems' No. 57000621).

Received: 11 April 2014 Accepted: 10 September 2014 Published: 13 Oct 2014

\section{References}

1. Banach, B: Sur les opérations dons les ensembles abstraits et leur application aux équations intégrales. Fundam. Math. 3, 133-181 (1922)

2. Suzuki, T: A new type of fixed point theorem in metric spaces. Nonlinear Anal. 71, 5313-5317 (2009)

3. Suzuki, T: Generalized distance and existence theorems in complete metric spaces. J. Math. Anal. Appl. 253, 440-458 (2001)

4. Suzuki, T: Several fixed point theorems concerning $\tau$-distance. Fixed Point Theory Appl. 2004, 195-209 (2004)

5. Tataru, D: Viscosity solutions of Hamilton-Jacobi equations with unbounded nonlinear terms. J. Math. Anal. Appl. 163, 345-392 (1992)

6. Vályi, I: A general maximality principle and a fixed point theorem in uniform space. Period. Math. Hung. 16, 127-134 (1985)

7. Włodarczyk, K, Plebaniak, R: Quasigauge spaces with generalized quasipseudodistances and periodic points of dissipative set-valued dynamic systems. Fixed Point Theory Appl. 2011, Article ID 712706 (2011)

8. Włodarczyk, K, Plebaniak, P: Kannan-type contractions and fixed points in uniform spaces. Fixed Point Theory Appl. 2011, Article ID 90 (2011)

9. Włodarczyk, K, Plebaniak, R: Contractivity of Leader type and fixed points in uniform spaces with generalized pseudodistances. J. Math. Anal. Appl. 387, 533-541 (2012)

10. Edelstein, M: On fixed and periodic points under contractive mappings. J. Lond. Math. Soc. 37, 74-79 (1962)

11. Wardowski, D: Fixed point theory of a new type of contractive mappings in complete metric spaces. Fixed Point Theory Appl. 2012, Article ID 94 (2012)

12. Secelean, NA: Iterated function systems consisting of F-contractions. Fixed Point Theory Appl. 2013, Article ID 277 (2013). doi:10.1186/1687-1812-2013-277

10.1186/1687-1812-2014-210

Cite this article as: Piri and Kumam: Some fixed point theorems concerning F-contraction in complete metric spaces. Fixed Point Theory and Applications 2014, 2014:210

\section{Submit your manuscript to a SpringerOpen ${ }^{\circ}$ journal and benefit from:}

- Convenient online submission

- Rigorous peer review

- Immediate publication on acceptance

- Open access: articles freely available online

- High visibility within the field

- Retaining the copyright to your article 